\title{
THE STUDY ON SEMIRIGID JOINT OF STEEL-CONCRETE COMPOSITE BEAM TO CFST COLUMN
}

\author{
Zhan Wang ${ }^{1, *}$, Jianrong $\operatorname{Pan}^{1}$ and Jixong Yuan ${ }^{2}$ \\ ${ }^{I}$ State Key Laboratory of Subtropical Building Science, South China University of Technology, Guangzhou, China \\ ${ }^{2}$ Department of Civil Engineering, Shantou University, Shantou, China \\ *(Corresponding author: E-mail: wangzhan@scut.edu.cn)
}

Received: 21 March 2008; Revised: 18 July 2008; Accepted: 29 July 2008

\begin{abstract}
The paper focused on the study on semirigid joint of steel-concrete composite beam to CFST column with stiffening ring. Two specimens were tested by incremental loading and cyclic loading. The finite element package ABAQUS was used to study the nonlinear behavior of such specimens. Shell elements were used to simulate the behavior of steel girder and steel tube. Continuum elements were used to simulate the behavior of concrete slab. The model was validated by comparing the computed values with experimental results. Based on the model, some factors, such as the dimensions of beam and column, were verified to influence on semirigid composite joint. A $M-\theta_{r}$ model for the composite joint was proposed.
\end{abstract}

Keywords: Finite element method, ABAQUS, semirigid joints, CFST column, Steel-concrete composite beam

\section{INTRODUCTION}

In the recent years, CFST (concrete-filled steel tubular) structures have been popularly applied in civil engineering. Because of the special formation of CFST column, the study on beam to column joint in high and high-rise building construction has been carried out all over the world.

The subject is a sub-item of the project, which is the study on restraining stiffness of joints of CFST frame. The previous researchers have done a lot of study on the project. Joint of steel beam to CFST column with stiffening ring, continuous web plate joint of steel beam to CFST column, and joint of steel beam to CFST column in frame structure have been researched. Some conclusions have been attained.

The first research was the stiffness of joint of steel beam to CFST column with stiffening ring. Chen et al. [1] used the finite element package ANSYS, created and analyzed the solid model of the joints, manufactured seven joints with stiffening ring to process joint test, and then verified the applicability of the finite element models with the experimental results. Base on the models, changed its dimension to confirm each factor influence on joint stiffness and created the joint's $M-\theta_{r}$ model, applied the joint's $M-\theta_{r}$ model to analyze the influence of both semirigid connection and joint stiffness on frame structure.

Wang et al. [2] made four continuous web plate joints of steel beam to CFST column. The joints were tested by using static test method. Experimental results showed the semirigid characteristic and transmutation state of connection areas of continuous web plate joint. Also the moment-rotation curve was gained.

Two CFST frames were tested by Chen and Wang [3]. The result was compared with the finite element analysis. The flexibility of connections and the rigid zones were considered in the member-bar model of the CFST frame. 
The paper put forward a joint, which is steel-concrete composite beam to CFST column with stiffening ring. The specimens were tested by monotonic loading and cyclic loading. The finite element package ABAQUS [5] has been used to simulate the behavior of such specimens. The finite element model has been validated by comparing the computed values with available experimental results. The analysis of joint of steel-concrete composite beam to CFST column is useful to designer for predicting the behavior of composite joint.

\section{FINITE ELEMENT ANALYSIS}

\subsection{Finite Element Model}

A three-dimensional finite element model with the following characteristics had been used in the study:

(1) Concrete slab and the core concrete of CFST - modeled with continuum element C3D8R (8-node linear brick, reduced integration with hourglass control).

(2) Steel beam and steel tube - modeled with shell element S8R5 (8-node doubly curved thin shell, reduced integration, five degrees of freedom per node).

(3) Steel reinforcement - modeled with truss element T3D2 (2-node linear displacement) embedded in the concrete slab.

Full composite action between steel beam and concrete slab was assumed. This is based on the assumption that there is no slip at both ends between the concrete slab and steel girder. The shear connectors were omitted in the finite element analysis, tie constraints in ABAQUS [4] were used to attach concrete slab to steel flange. Surface-to-surface contact (ABAQUS/Standard) was used to simulate the contact between steel tube and concrete filled in the tube. A typical three-dimensional model used in the study is shown in Figure 1.

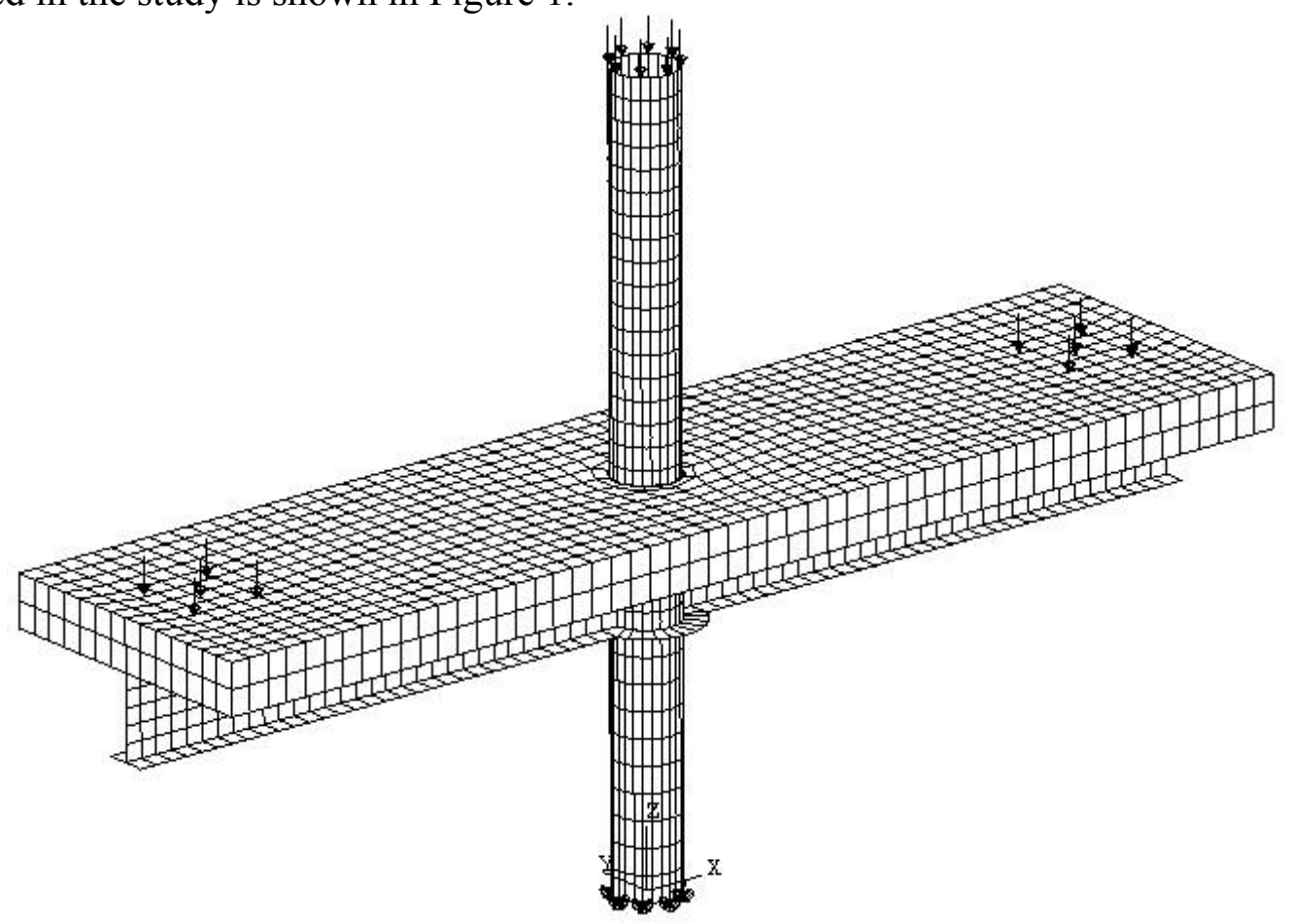

Figure 1. Finite Element Mesh 


\subsection{Material Modeling}

Steel was assumed to behave as an elastic-plastic material with strain hardening in both tension and compression. Strain hardening had been modeled based on incremental plasticity theory. The idealized stress-strain curve used in the numerical analysis is shown in Figure 2. Material properties of steel are specified using the elastic-plastic with strain hardening options. For this purpose, ABAQUS [4] requires the input of the Young's modulus, $E_{\mathrm{s}}$; Poisson's ratio, $\gamma_{\mathrm{s}}$; yield stress, $f_{\mathrm{sy}}$; and the ultimate stress, $f_{\text {su, }}$, shown in Table 1.

Table 1. Parameters of Steel Material

\begin{tabular}{|c|c|c|c|c|c|}
\hline \multicolumn{2}{|c|}{ Material } & $\begin{array}{c}\text { Yield strength } \\
(\mathrm{MPa})\end{array}$ & $\begin{array}{c}\text { Ultimate strength } \\
(\mathrm{MPa})\end{array}$ & $\begin{array}{c}\text { Young's modulus } \\
(\mathrm{MPa})\end{array}$ & $\begin{array}{c}\text { Poisson's } \\
\text { ratio }\end{array}$ \\
\hline \multicolumn{2}{|c|}{ Steel tube } & 350.0 & 460.0 & $2.06 \mathrm{E}+5$ & 0.30 \\
\hline \multirow{3}{*}{ Steel girder } & Flange & 270.0 & 370.0 & $2.06 \mathrm{E}+5$ & \multirow{2}{*}{0.30} \\
\cline { 2 - 5 } & Web & 290.0 & 390.0 & $2.06 \mathrm{E}+5$ & \\
\hline
\end{tabular}

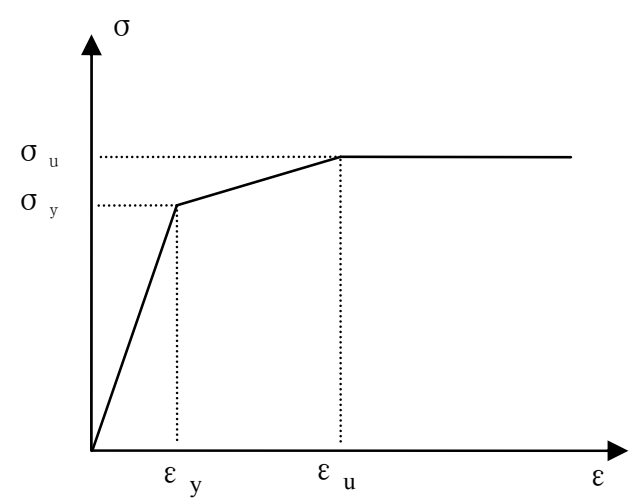

Figure 2. Stress-Strain Relationships for Steel

There are three concrete material models in ABAQUS [4]: concrete smeared cracking, cracking model for concrete, and concrete damaged plasticity. Among these models, the concrete damaged plasticity model is designed for applications with concrete subjected to monotonic and cyclic loadings and has good convergence characteristics. The concrete damaged plasticity was used to simulate concrete slab. The extended Drucker-Prager model was used to simulate the core concrete of CFST.

For concrete, the elastic properties are defined by the elastic option and its compressive stress-strain relationship outside the elastic range is specified using the concrete option. The values of Young's modulus, $E_{\mathrm{c}}$; Poisson's ratio, $\gamma_{\mathrm{c}}$; and the values of $f_{\mathrm{c}}$ for several values of $\varepsilon_{\mathrm{c}}$ and the corresponding values given by $\left(\varepsilon-f_{\mathrm{c}} / E_{\mathrm{c}}\right)$ are required as input. The material properties of concrete are specified in Table 2 .

Table 2. Parameters of Concrete Material

\begin{tabular}{|c|c|c|c|c|}
\hline Material & $\begin{array}{c}\text { Uniaxial ultimate } \\
\text { compressive strength (MPa) }\end{array}$ & $\begin{array}{c}\text { Uniaxial ultimate } \\
\text { tensile strength (MPa) }\end{array}$ & $\begin{array}{c}\text { Young's } \\
\text { modulus (MPa) }\end{array}$ & $\begin{array}{c}\text { Poisson's } \\
\text { ratio }\end{array}$ \\
\hline Concrete & 25.50 & 2.32 & $3.20 \mathrm{E}+4$ & 0.20 \\
\hline
\end{tabular}




\subsection{Analysis of FEM Results}

While solving equation, implicit solution (ABAQUS/Standard) was adopted. The initial and final load increments as well as the allowable minimum and maximum load increments are required in input file. The program iterates to reach the equilibrium condition for the initial load increment and all the subsequent increments automatically.

The ABAQUS analysis results include all stress and strain components, equivalent stress and total deformation. Through particular analysis, the details under loading were understood, and the information contributed to comprehend the mechanics behavior of joints. Analysis result of finite element offers guidance for design and measure of joint test.

\section{THE EXPERIMENT OF JOINT}

\subsection{Design of Experiment}

Two one-third scale joint specimens were manufactured according to Zhong [5]. The section of steel tube was $\Phi 159 \times 5$, and the section of steel beam was HN200×100 $\times 5.5 \times 8$. The thickness of concrete slab was $120 \mathrm{~mm}$, and the width of concrete slab was $700 \mathrm{~mm}$. Longitudinal reinforcements were $\Phi 12-120$. Lateral reinforcements were $\Phi 6-70$. Shear connectors were $\Phi 16 \times 90$, yield strength, $390 \mathrm{MPa}$; ultimate strength, $440 \mathrm{MPa}$. The cross-section of the composite beam is shown in Figure 3. The two specimens were tested by incremental loading and cyclic loading. Loading system is shown in Table 3, Figure 4, and Figure 5.

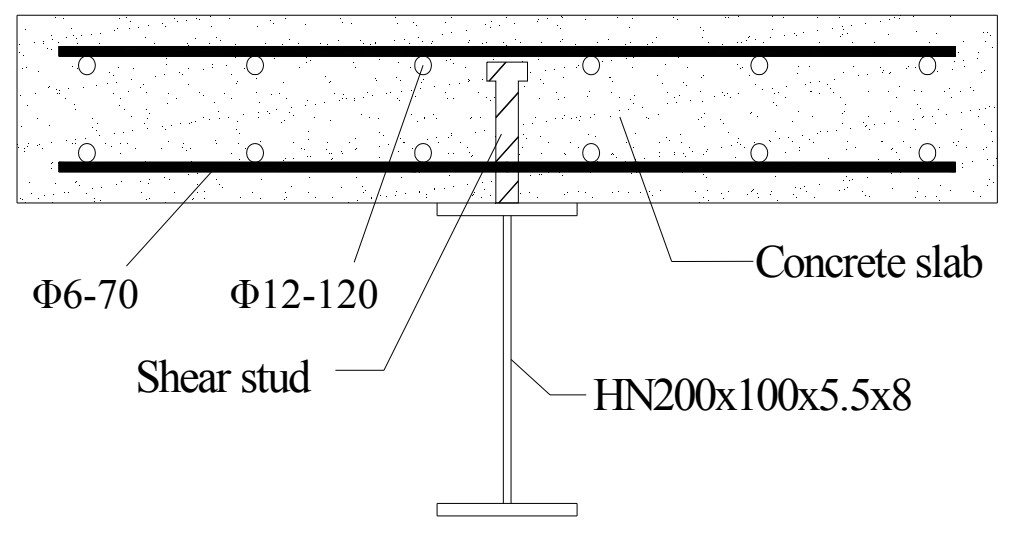

Figure 3. Cross-Section of Composite Beam

Table 3. Loading System

\begin{tabular}{|c|c|c|}
\hline Number & CFST $(\mathrm{kN})$ & Composite beam $(\mathrm{kN})$ \\
\hline $\mathrm{HN} 200 \mathrm{~A}$ & $0 \rightarrow 400$ & $0 \rightarrow 10 \rightarrow 20 \rightarrow 30 \rightarrow 40 \rightarrow 50 \rightarrow 60 \rightarrow 65 \rightarrow 70 \rightarrow 75 \rightarrow 80 \rightarrow 85 \rightarrow 90 \rightarrow 95$ \\
\hline $\mathrm{HN} 200 \mathrm{~B}$ & $0 \rightarrow 400$ & $0 \rightarrow 20,0 \rightarrow 40,0 \rightarrow 60,0 \rightarrow 80,0 \rightarrow 95$ \\
\hline
\end{tabular}




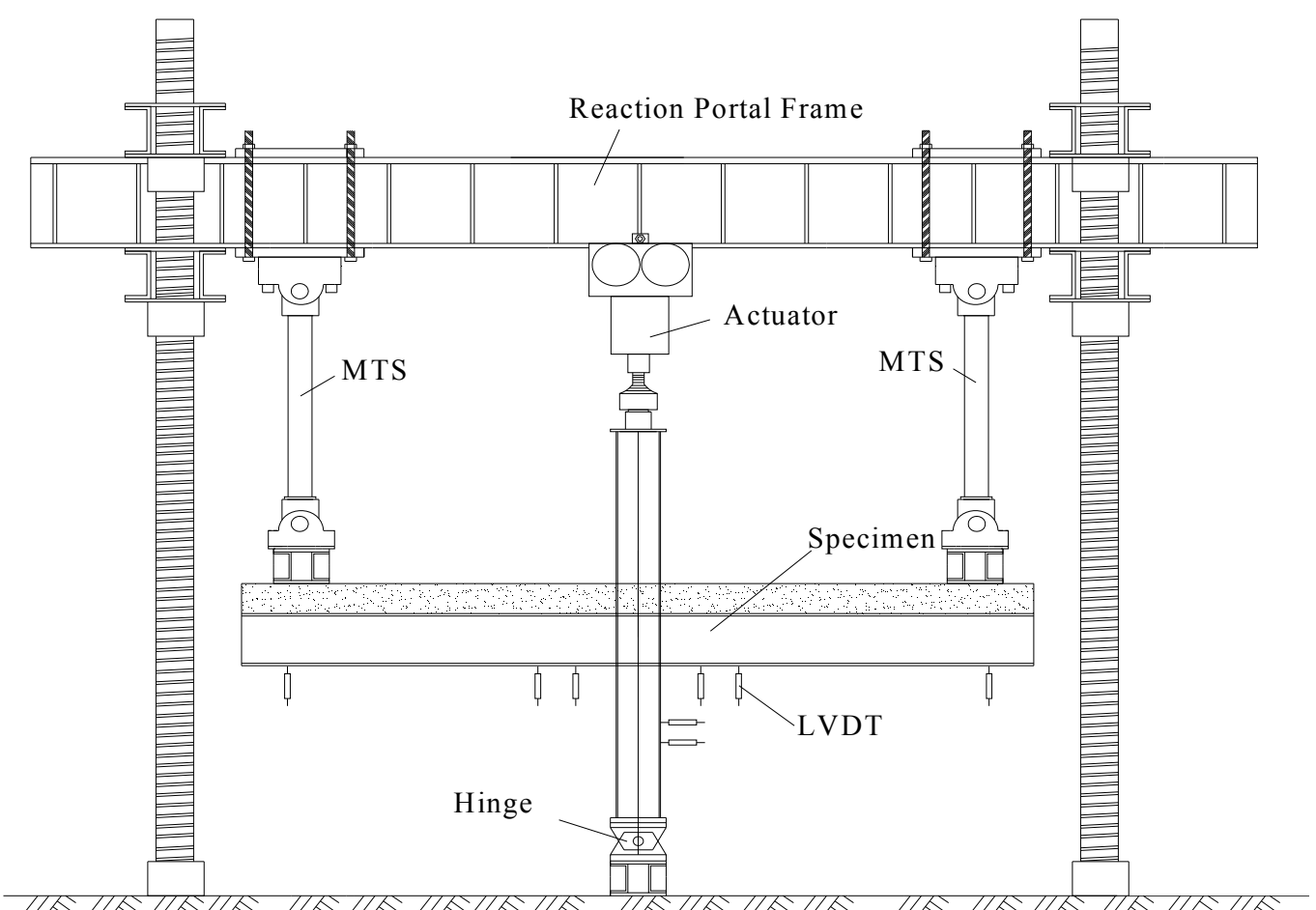

Figure 4. Sketch of Loading System

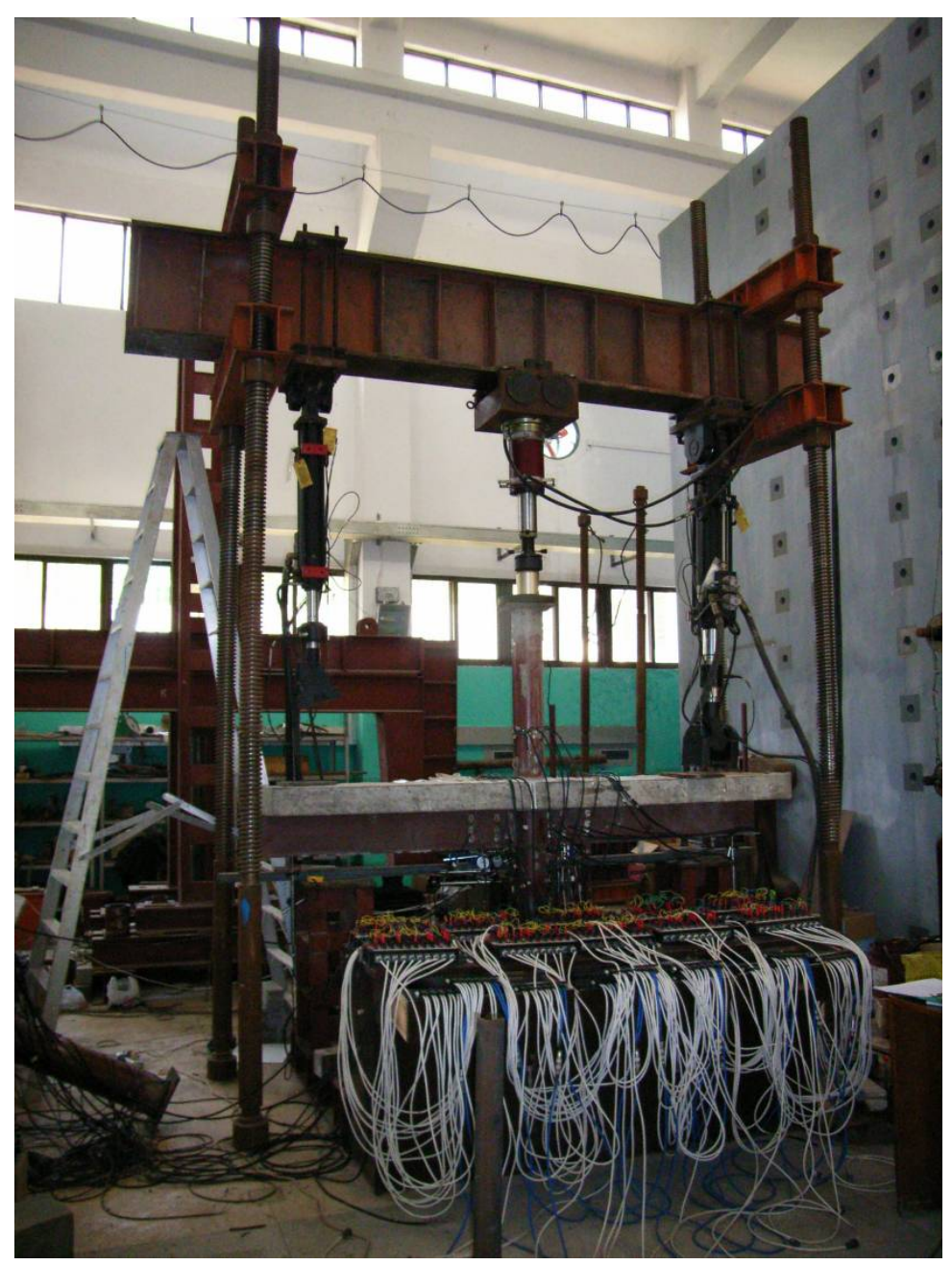

Figure 5. Specimen Loading 


\subsection{Analysis of Experiment Results}

In area of negative moment of the joint, there was no obvious stress concentration in the top flange of steel beam. Elastic neutral axis and plastic neutral axis were close to top flange. The joint was damaged owing to the lower flange buckling firstly. The concrete slab was tensioned and cracked in the region about $300 \mathrm{~mm}$ from the joint.

Load-strain curves of the steel beam section are shown in Figure 8. From zero point to $200 \mathrm{~mm}$ (the height of steel beam) of the y-axis, strains of gauge 44\#, 3\#, 2\#, 1\#, 33\# (see Figure 6) are specified. From the figures we can see that plane cross-section is acceptable in design of the joint. Figure 9 is load-strain of longitudinal rebar 20\#, 19\#, 7\#, 8\# and 9\# (see Figure 7). At the same load value, the strain values of rebar $20 \#, 19 \#, 7 \#, 8 \#$ are increasing, while $9 \#$ is smaller. It may be due to that rebar end was weld end plate. The cyclic load-deflection curves of specimen HN200B are shown in Figure 10. Precise values of the specimen HN200B were not attained from experiments. However, all curves are approximately linear.

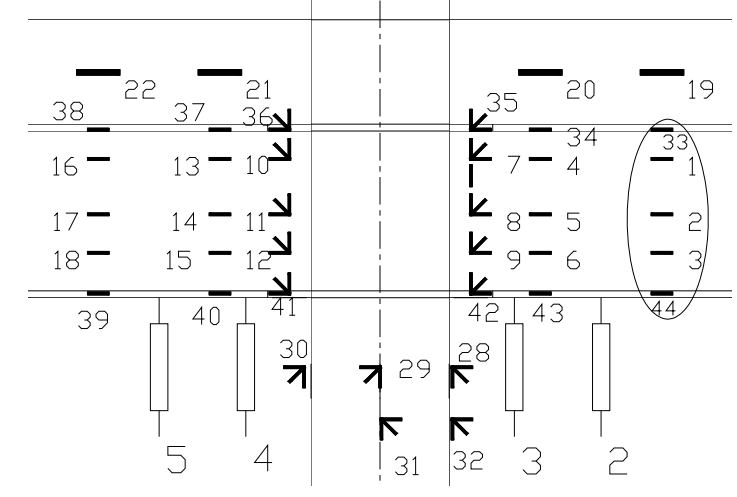

Figure 6. Gauges Layout of Joint

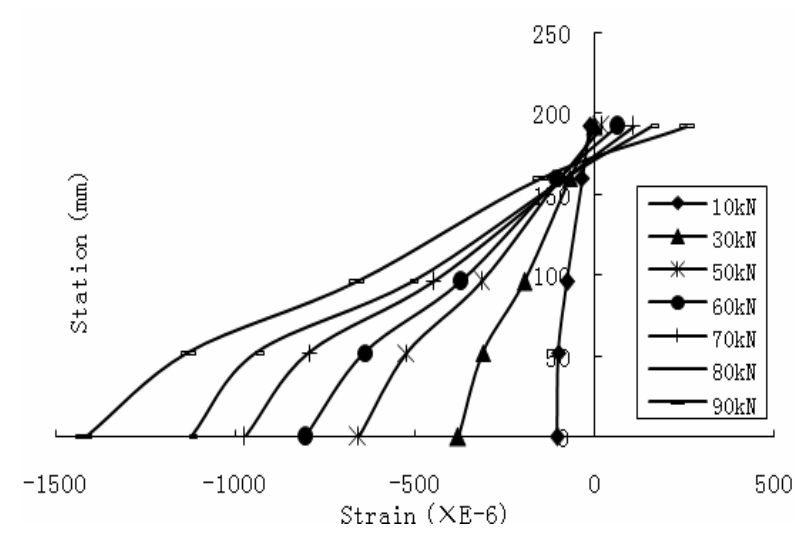

Figure 8. Load-strain of Cross-Section

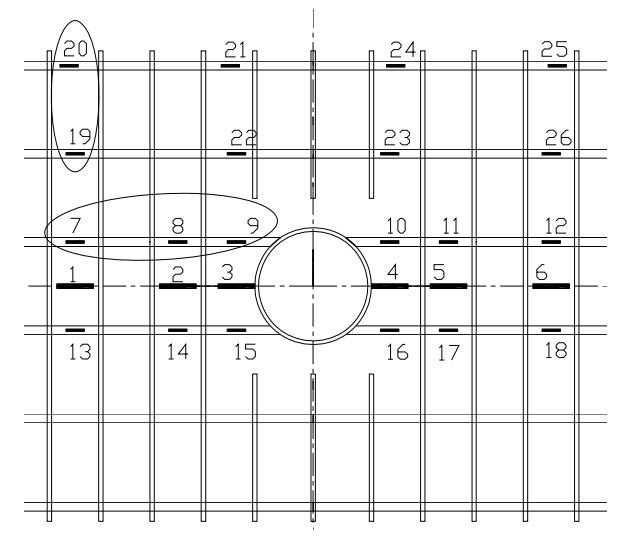

Figure 7. Gauges Layout of Rebar

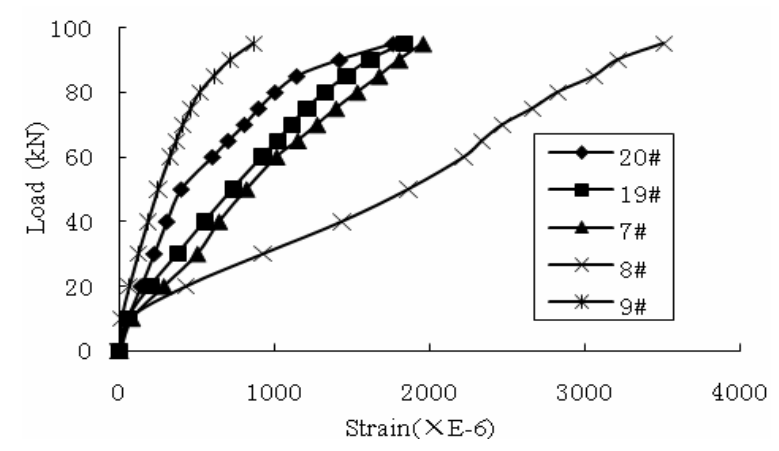

Figure 9. Load-strain of Longitudinal Rebar 


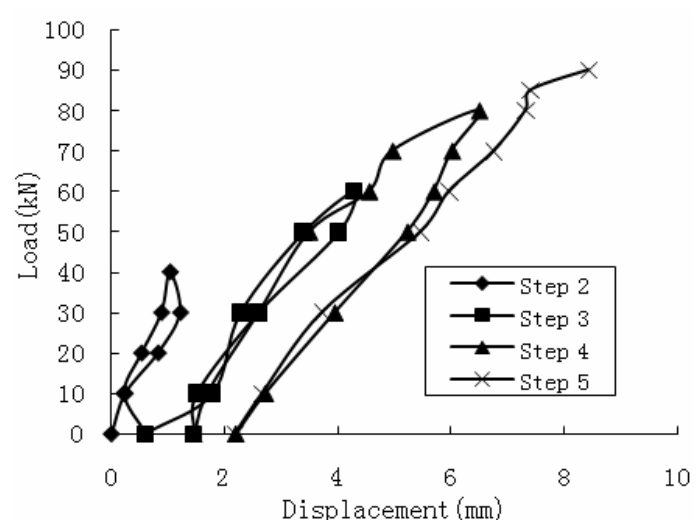

Figure 10. Load-displacement Curves for Specimen HN200B

\section{COMPARISONS OF EXPERIMENT AND FEM RESULTS}

Strain at each direction, stress at each direction, ultimate load and total deformation were obtained from the finite element analysis. These results have been compared with the corresponding experimental results. The comparison of strains of steel beam section (see Figure 6) is presented in Figure 11 and the comparison of strains of rebar 7\# (see Figure 7) in Figure 12. The values of finite element analysis are similar to those of experimental results. The load-deflection curves are shown in Figure 13. Close agreement between the finite element and experimental results can be observed. However, there seems to be some deviation between the results. The discrepancy may be due to the inadequacy in concrete modeling. The concrete is not a homogeneous material and the concrete material model used in the analysis significantly simplifies the actual behavior. Constitutive calculations are performed independently at each integration point in the finite element model. However, when a crack developed in the concrete during the experiment, the moment of inertia of the whole section decreased and the ratio of the deformation to loading increased considerably.

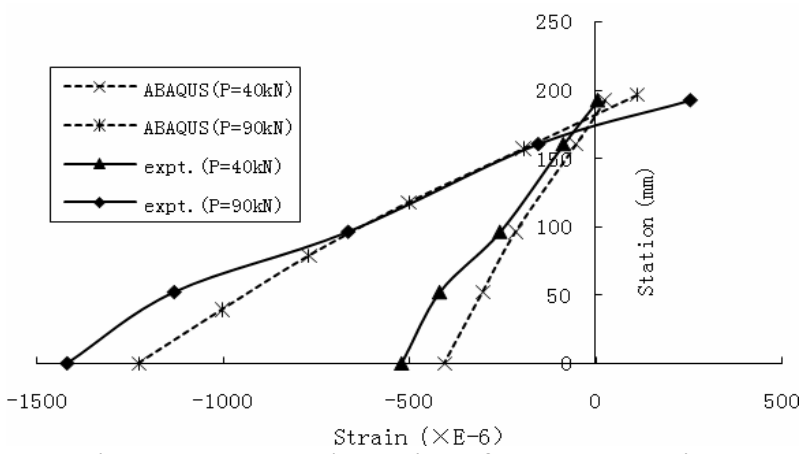

Figure 11. Load-strain of Cross-Section

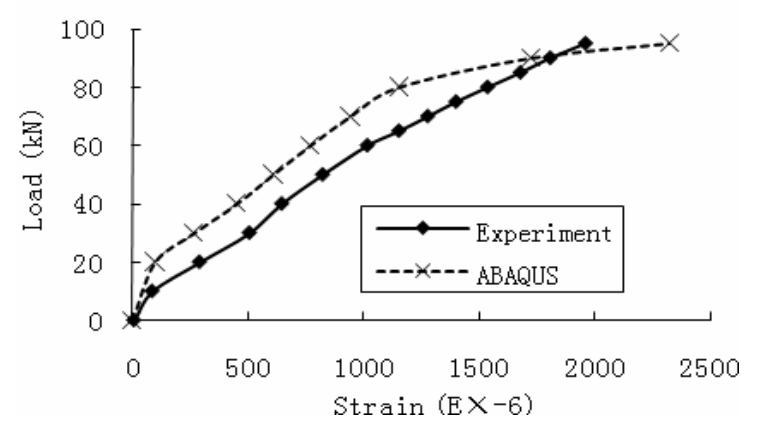

Figure 12. Load-strain of Rebar 7\# 


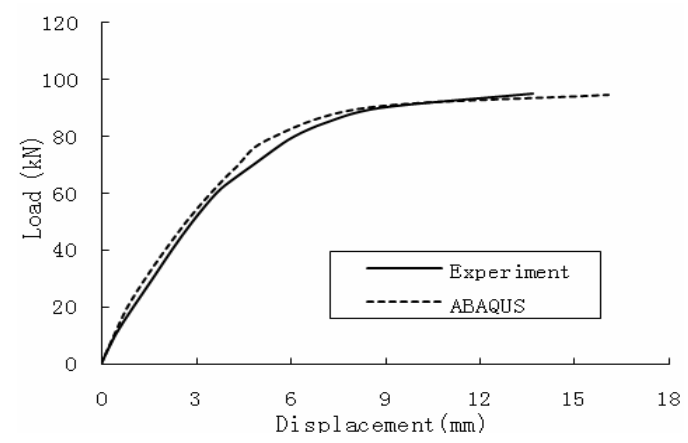

Figure 13. Load-displacement Curves for HN200A

\section{RIGIDITY OF COMPOSITE JOINT}

The connection of beam to column transfers a set of generalized force components including axial force, shear, moment, and torsion. The influence of torsion can be neglected in plane problem. For most connections, axial deformation and shearing deformation are relatively very small and cal also be neglected. Therefore, only rotational deformation is considered generally. The relative rotation may be defined as shown in Figure 14.

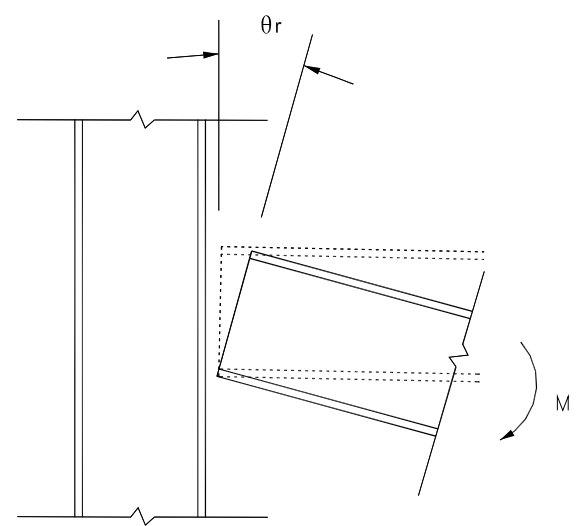

Figure 14. Relative Rotation between Beam and Column

The moment-rotation curves are shown in Figure 15. The experimental results illustrated that the composite joint is semirigid, not fixed. The finite element results are in relatively close agreement with the corresponding experimental results. The finite element model for the joint is valid and acceptable, although there are still some differences between experimental results and finite element analysis.

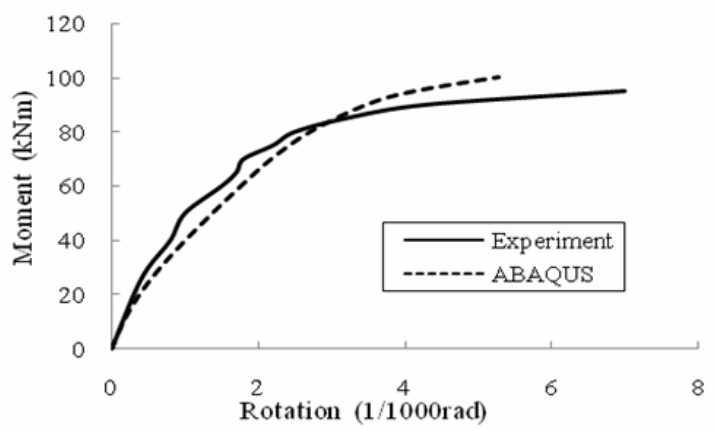

Figure 15. Moment-rotation Curves for HN200A 


\subsection{Analysis of Influence Factors}

For a typical joint, influencing factors on its rigidity include geometrical and mechanical properties. Different joint must account for the contribution of the different components. In this paper, mainly geometrical factors are considered. Influencing factors are shown in Figures 16-20, including height of steel beam, width of steel beam flange, diameter of steel tube, equivalent width of concrete slab and height of concrete slab. Others are not ploted here because of their little influence. According to the analysis, height and equivalent width of concrete slab and height of steel beam are the major factors. More details were provided by Pan [6].

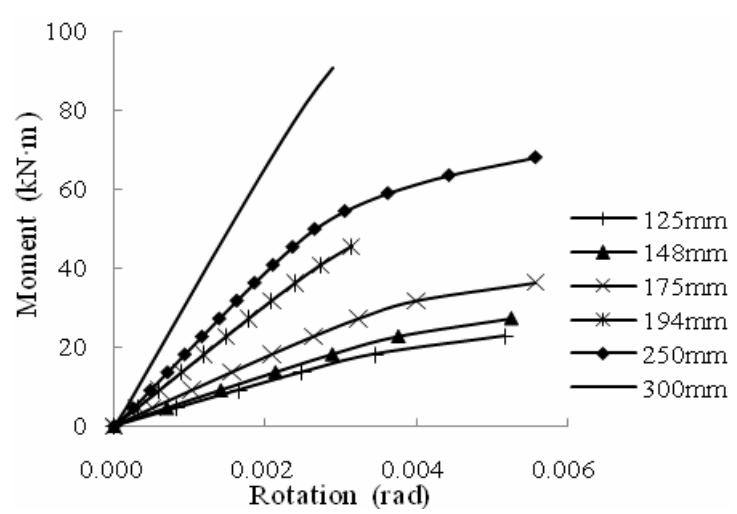

Figure 16. $M-\theta_{r}$ Curves on the Height

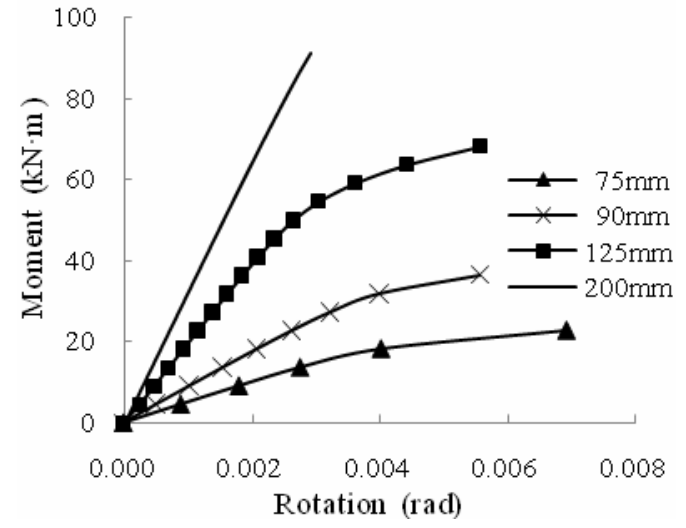

Figure 17. $M-\theta_{r}$ Curves on Width of of Steel Beam Web Steel Beam Flange

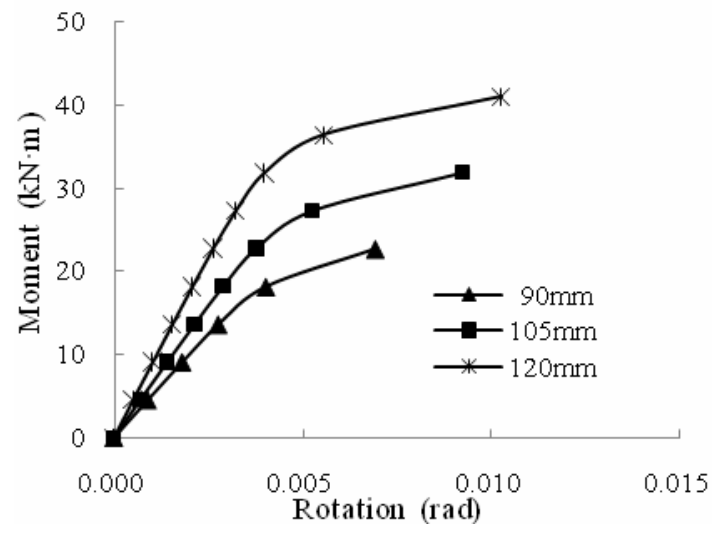

Figure 19. $M-\theta_{r}$ Curves on Equivalent of Steel Tube width of Concrete Slab

Figure 18. $M-\theta_{r}$ Curves on Diameter

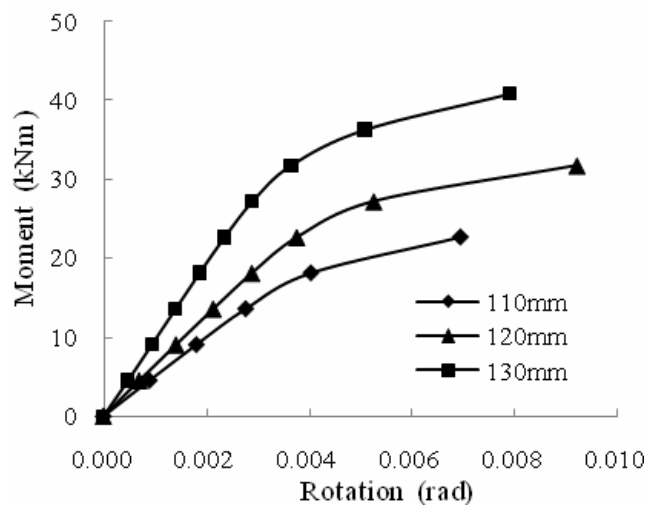

Figure 20. $M-\theta_{r}$ Curves on Thickness of Concrete Slab 


\section{2}

$M-\theta_{r}$ Model

According to the analytical theory of semirigid steel frame in reference Chen and Lui [7] that introduced Colson-Louveau and Kishi-Chen models, and the achievements that the previous researchers had been attained, a power function is used as the $M-\theta_{r}$ model for the composite joint in Eq. 1. Because of the assumption of full composite action between the concrete slab and steel beam in the analysis, the influencing factors, such as shear studs and reinforcement, are ignored. Only geometrical factors are considered. In Colson-Louveau and Kishi-Chen models, $M_{u}$ is the ultimate moment of connection, which is obtained by analytical method generally. Considering that the failure may happen in beam for the joint, therefore, let $M_{u}$ be ultimate moment of beam.

$\theta_{r}=\frac{M}{K\left[1-\left(M / M_{u}\right)^{C}\right]}$

Where $\mathrm{M}(\mathrm{N} \cdot \mathrm{m})$ is the beam moment of joint, $\theta_{r}(\mathrm{rad})$ is the relative rotation between beam and column, $C$ is a fitting parameter, $C=4.118$; $K$ is a standard constant, and is determined by Eq. 2 .

$$
K=d_{s}^{0.434} t_{s}^{0.048} b_{j}^{0.364} h_{s}^{0.612} b_{s}^{0.398} h_{c}^{0.981} b_{c}^{0.913}
$$

Where $d_{\mathrm{s}}(\mathrm{mm})$ is the diameter of steel tube, $t_{\mathrm{s}}(\mathrm{mm})$ is the thickness of steel tube, $b_{\mathrm{j}}(\mathrm{mm})$ is the width of stiffening ring, $h_{\mathrm{s}}(\mathrm{mm})$ is the height of steel beam, $b_{\mathrm{s}}(\mathrm{mm})$ is the width of steel beam flange, $h_{\mathrm{c}}(\mathrm{mm})$ is the thickness of concrete slab, $b_{\mathrm{c}}(\mathrm{mm})$ is the equivalent width of concrete slab.

\section{CONCLUSION}

A numerical study was carried out by using the software package ABAQUS. The finite element analysis was validated by experimental results. There are still some discrepancies between finite element and experimental values. More vigorous modeling especially for concrete material is essential in order to achieve better accuracy in theoretical prediction.

The joint between steel-concrete composite beam and CFST column with stiffening ring is semirigid. Height and equivalent width of concrete slab and height of steel beam are the major influence factors on semirigid composite joint. A $M-\theta_{r}$ model of such joint was proposed.

The development of such an analytical model will be useful to designers as it will reduce the need of carrying out expensive and time consuming full-scale tests to predict the behavior of the joints.

\section{ACKNOWLEDGEMENTS}

The authors gratefully acknowledge the research grant (50378053) provided by National Natural Science Foundation of China. Main research work was carried out in Shantou University and South China University of Technology in China. 


\section{REFERENCES}

[1] Chen, J., Wang, Z. and Yuan, J.X., "The Study on the Stiffness of Joint of Steel Beam to CFT Column with Stiffening Ring”, Journal of Building Structures, 2004, Vol. 25, No. 4, pp. 43-49.

[2] Wang, Z., Yuan, J.X., Pan, J.R. and Chen, J., "The Study on Semirigid Joint of CFST Frame", Advanced Steel Construction, 2006, Vol. 2, No. 4, pp. 389-399.

[3] Chen, X. and Wang, Z., "Research on the Rigidity of the Joint in Concrete-filled Steel Tubular Frame", Journal of Harbin Institute of Technology, 2007, Vol. 39 (SUPPL. 2), pp. 381-384.

[4] ABAQUS Theory Manual, ABAQUS User's Manual, Hibbit, Karlsson and Sorensen, Inc., USA.

[5] Zhong, S.T., "The Concrete-Filled Steel Tubular Structures (Third Edition)", Tsinghua University Press, 2004.

[6] Pan, J.R., "The Study on Joint Performance of Steel-Concrete Composite Beam to CFT Column", Shantou University Press, 2006.

[7] Chen, W.F. and Lui, E.M., "Stability Design of Steel Frames”, CRC Press, 1991. 